\title{
sciendo
}

CIVIL AND ENVIRONMENTAL ENGINEERING REPORTS

E-ISSN 2450-8594

CEER 2019; 29 (2): 074-100

DOI: 10.2478/ceer-2019-0018

Original Research Article

\section{VIBRATION CONTROL DEVICES FOR BUILDING STRUCTURES AND INSTALLATION APPROACH: A REVIEW}

\author{
Waseem SARWAR ${ }^{1}$, Rehan SARWAR ${ }^{2}$ \\ ${ }^{1}$ Department of Civil Engineering, Southeast University, Nanjing, China \\ ${ }^{2}$ Department of Computer Science, Comsats University Islamabad, Abbottabad Campus
}

\begin{abstract}
Retrofit and structural design with vibration control devices have been proven repeatedly to be feasible seismic hazard mitigation approach. To control the structural response; supplemental energy dissipation devices have been most commonly used for energy absorption. The passive control system has been successfully incorporated in mid to high rise buildings as an appropriate energy absorbing system to suppress seismic and wind-induced excitation. The considerable theses that are highlighted include vibration control devices, the dynamic behavior of devices; energy dissipation mechanism, devices installation approach and building guidelines for structural analysis and design employing vibration control devices also, design concern that is specific to building with vibration control devices. The following four types of supplemental damping devices have been investigated in this review: metallic devices, friction devices, viscous fluid devices, and viscoelastic devices. Although numerous devices installation techniques available, more precisely, devices installation approaches have been reviewed in this paper, including Analysis and Redesign approach (Lavan A/R), standard placement approach, simplified sequential search algorithm, and Takewaki approach.
\end{abstract}

Keywords: vibration control devices, building structures, mechanical behavior, installation approach, design consideration

\footnotetext{
${ }^{1}$ Corresponding author: Department of Civil Engineering, Southeast University, Nanjing, China, e-mail: waseem_seu@outlook.com
} 


\section{INTRODUCTION}

Supplemental vibration control devices have been incorporated in the number of building structures to scale down the structural reactions induced due to the earthquake excitation and strong winds. Structural vibration control devices dissipate the input energy from the seismic activity or strong winds reducing the severe harmful vibration and consequence on the most critical members of the building [1]. Passive control devices have appeared as a unique mechanism component that is commonly incorporated inside the building to dissipate a significant amount of the earthquake energy. The concept of applying a passive control system inside a building to dissipate a significant input energy amount and control the earthquake vibration start with the idea and experiment by [2]. Authentic analytical and experimental research performed on these passive control devices significantly confirm their suitability for the real applications in structures subjected to earthquake events [3-7]. The critical design and modeling concern for researchers was the proper distribution of suitable devices in the building; because devices position will directly influence the responses of structure, the effectiveness of devices throughout the structure and the cost of the devices to achieve the desired response according to the building codes [8].

Nevertheless, buildings design codes do not establish the optimal damper placement approach [9]. Ordinarily, vibration control devices are often installed in buildings according to rules of thumb, and common local practices either these rules may include equal damping distribution to story stiffness, placing dissipative devices at a single story or uniform damper distribution. These methods may lead to an expensive design with some dampers different sizes and damper installation configurations that are very difficult to validate as optimal. The specific Project limitations, such as internal architectural constraints, also contribute to devices position decisions. Optimization analysis utilized to describe the ideal dynamic coefficient for the energy dissipation devices; estimate the response of devices, distributions across the height of a building and the conclusion from the research demonstrate those vibration control devices should be installed in the lower stories in case of uniform story stiffness [10].

This review paper focuses mainly on the critical characteristics of energy dissipation devices, including the dynamic response of devices, and their placement techniques in buildings for vibration control also highlighted. Primarily describe the analytical modeling of passive control devices, mechanical and dynamic characteristics of four different most commonly used vibration control devises, and address the energy dissipation mechanism. Also included in the discussion the installation techniques of vibration control devices 
in building structures and the comprehensively describe the damping distribution in the building according to the engineering demand parameters. Furthermore, provide the seismic design codes to estimate the actual response of the building and future recommendations for research.

\section{THE PASSIVE CONTROL SYSTEM, EARLIER AND RECENT DEVELOPMENTS}

The passive control system has its unique characteristics, and their typical forcedeformation features which dramatically influences the modeling of these devices, types of material used in devices and those of the building structure in which they are installed according to the standard building codes and guidelines, considerable characteristics of passive control system are given in Table 1.

Table 1. Considerable characteristic of the passive control devices

\begin{tabular}{|c|c|c|c|c|}
\hline $\begin{array}{l}\text { Passive } \\
\text { control System }\end{array}$ & $\begin{array}{l}\text { Metallic } \\
\text { devices }\end{array}$ & $\begin{array}{l}\text { Friction } \\
\text { devices }\end{array}$ & $\begin{array}{l}\text { Fluid Viscous } \\
\text { Devices }\end{array}$ & $\begin{array}{l}\text { Viscoelastic } \\
\text { devices }\end{array}$ \\
\hline Advantages & $\begin{array}{l}\text {-High } \\
\text { reliability } \\
\text {-Insensitive to } \\
\text { temperature } \\
\text {-Relatively } \\
\text { Inexpensive } \\
\text { - Easy to } \\
\text { construct }\end{array}$ & $\begin{array}{l}\text {-High energy } \\
\text { dissipation per } \\
\text { cycle } \\
\text {-Insensitive to } \\
\text { environmental } \\
\text { conditions }\end{array}$ & $\begin{array}{l}\text {-High } \\
\text { reliability } \\
\text {-Activated at } \\
\text { low } \\
\text { displacement } \\
\text {-Damping } \\
\text { force out of } \\
\text { phase with } \\
\text { structure } \\
\text { elastic forces }\end{array}$ & $\begin{array}{l}\text {-High } \\
\text { reliability } \\
\text {-Cost-effective } \\
\text {-Provide } \\
\text { restoring force }\end{array}$ \\
\hline Disadvantages & $\begin{array}{l}\text {-Highly } \\
\text { Nonlinear } \\
\text { Behavior } \\
\text {-Must be } \\
\text { Replaced after } \\
\text { Major } \\
\text { Earthquake }\end{array}$ & $\begin{array}{l}\text {-Reliability } \\
\text { concern } \\
\text {-Highly } \\
\text { Nonlinear } \\
\text { response } \\
\text {-Adds Large } \\
\text { Initial Stiffness }\end{array}$ & $\begin{array}{l}\text {-Higher cost } \\
\text {-Some cases } \\
\text { Liquid leakage } \\
\text {-The nonlinear } \\
\text { analysis } \\
\text { required for } \\
\text { application a }\end{array}$ & $\begin{array}{l}\text {-Limited } \\
\text { deformation } \\
\text { capacity } \\
\text {-Temperature } \\
\text { and frequency } \\
\text { dependence }\end{array}$ \\
\hline
\end{tabular}

Reliable and solid analytical and experimental investigations performed on passive control devices and declare their suitability for installation in buildings subjected to seismic events $[4,6,11-14]$. The development of modeling and 
design guidelines and structural code requirements for the application of seismic control devices has been significant in publicizing the utilize of a passive control system [1,7]. A real application of friction devices installed in a multistory public building to control the building response can be seen in Fig. 1.

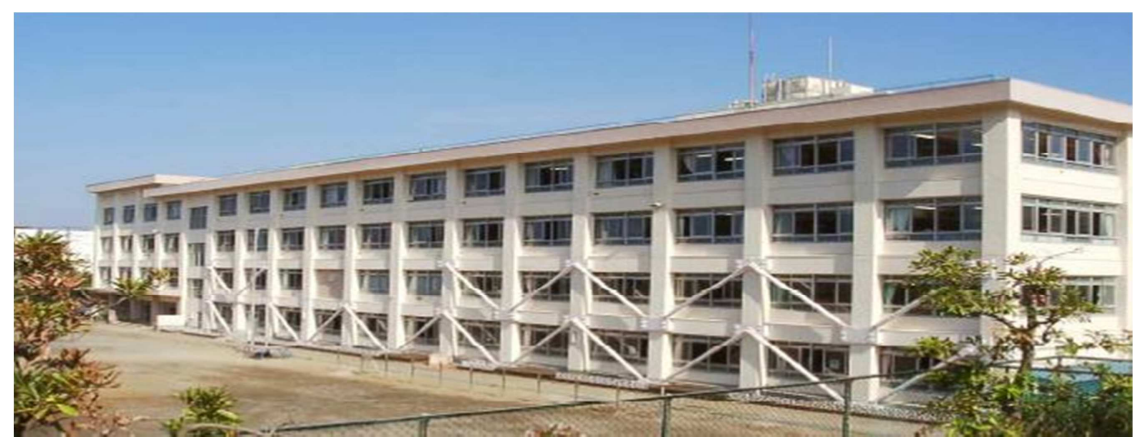

Fig. 1. Application of friction devices [15]

\subsection{Metallic devices}

Metallic devices have high resistance to fatigue and employ the hysteretic behavior of device metals within the inelastic limit. The reaction forces of the metallic devices, mainly, depends on the non-linear force-deformation behavior and nature of the device. An extensive range of supplemental energy dissipation devices that use flexure, shear and material deformation within the plastic limit has been considered. The critical and advantageous features of these energy dissipation devices are their positive and excellent hysteretic behavior, fatigue properties at low-cycle, solid reliability, and corresponding affectless to variation in environmental conditions. Besides, these damping devices are comparatively cost-effective, and their stable energy dissipation characteristics will be unchangeable and reliable over the years. The disadvantages of metallic devices are the non-linear response and limited working cycles. The commonly used metallic device can be seen in Fig. 2, and Fig. 3 represents the typical force-displacement behavior. Most Commonly used X-shaped metallic plate devices are well known among the metallic energy dissipation devices. The devices consist of the parallel metallic plate utilized to be installed inside a building, $\mathrm{RC}$ or steel frame bay between a diagonal, chevron brace or other brace system and the overlying beam. Consequently, the metallic devices primarily resist or overcome the horizontal reactions related to inter-story drift due to the flexural strain of the metallic plates. Moreover, because of the internal reaction force, the metallic elements yield and thus produce excellent energy dissipation properties. The conventional configuration of the metallic elements 
produces approximately reliable yielding over the surface of the metallic elements.

Bechtel Power Corporation introduced X-shaped metallic plate devices composed of multiple $\mathrm{X}$-shaped plates. The wide ranges of experimental and analytical investigation of these devices have been considered [16, 17]. Computational and dynamic structural analysis and the application of metallic plate devices, and their response can also found $[12,18]$.

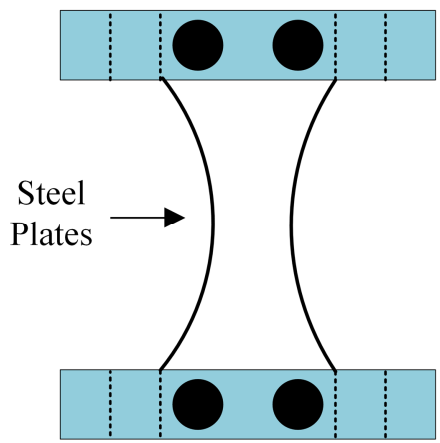

Fig. 2. A typical added damping and stiffness (ADAS) device

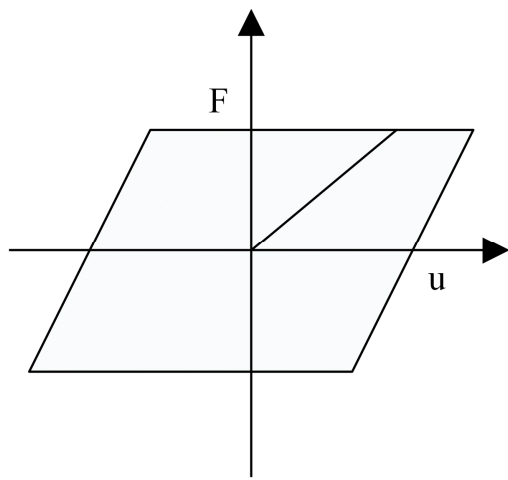

Fig. 3. Idealized force displacement loop of the metallic device

There are many exciting substitutes to improve the Newton-Raphson approach. The diversity of the metallic bracing energy dissipaters have been proposed in various countries such as Italy, New Zealand, and the United States of America. The outcomes of these investigations demonstrate that the X-shaped metallic devices disclosed excellent performance and confirmed to be balanced under working axial loads in the devices. Metallic devices have been successfully incorporated in the buildings as part of seismic rehabilitation projects in RC buildings [13, 19-21]. 
Idealized analytical models, bilinear or elastic-perfectly plastic with postyielding strain-hardening behavior have been adopted by researchers $[17,18$, 22-25]. The Ramberg-Osgood formulas [26] have been utilized to fit best the test data obtained from testing of the metallic devices [27, 28]. An expansion of the Özdemir model has also been developed to approach different situations to associate multi-directional axial loadings conditions [29]. The mathematical approach of these devices has been taken to another stage of clarification by proposing a mechanics-based approach [30]. An inelastic constitutive model combined with high strain theories has been used to propose the forcedeformation model of a device. A finite element generation based on a surface plasticity model has been followed to anticipate the device behavior under seismic and wind loadings [31, 32]. The characteristic features of these mechanics-based models are that they can be utilized to characterize the hysteretic models logically for any reasonable geometric configuration of the device reducing the concerns for component testing. The influence of the metallic devices in developing the earthquake resistance of a structure depends on the suitable choice of the parameters which may influence their response significantly. The crucial parameters effect in the design of devices is the ratios of steel bracing stiffness to device stiffness, a device with the stiffness of steel bracing to device stiffness, and also the stiffness of the relevant story of the structure $[12,33,34]$.

\subsection{Friction devices}

Friction energy dissipation devices have been proposed and successfully installed in many engineering applications. Frictional supplemental devices dissipate a large portion of input energy by the friction mechanism, and they have exceptional features, and the energy dissipation behavior is less affected by the working frequency, working loading cycles, or the variation in environmental conditions. Friction devises response such as force response is modeled by Coulomb friction and exhibits that rigid-plastic behavior. The $\mathrm{X}$ braced energy dissipation device was developed [35], and in case of these type of supplemental devices, the device supporting steel braces in a building included X-braced frictional damping devices. When the active load transfer to the supplemental device, the brace experience tension and incorporated slippage at the most critical frictional point. Sliding contact friction device mathematical model described by equation 1 , where $\mu$ is friction coefficient and $\mathrm{N}$ is a reaction force across the device at the sliding surface.

$$
P=\mu N \operatorname{sgn}(\dot{u})
$$


Friction devices are not sensitive to thermal effects, have stable behavior and possess balanced hysteretic behavior for different and high impact number of cycles under a variety of excitation conditions [36-39]. It is aimed to protect the structural components during high impact seismic loadings. Many models have been developed and employed to characterize the hysteretic behavior of these devices, and the most typical is the bilinear model, in which the forcedeformation relationship is given regarding an elastic-perfectly plastic magnification [40-43]. multi-levels stiffness model has also been developed to define the channels from stick to slipcases in a device with changing stiffness $[44,45]$. The structural deformations are greatly restricted until the friction force is decreased; thus, the dissipative energy devices add additional stiffness to the structure. In case restoring force, the mechanism is not provided within the friction devices system, deformation in the building produce after the seismic event which may be permanent. However, to reduce the deformation issues, few self-centering friction devices have been introduced [46, 47]. The commonly used X-braced friction device can be seen in Fig 4, and the Fig 5, represents the typical force-displacement behavior.
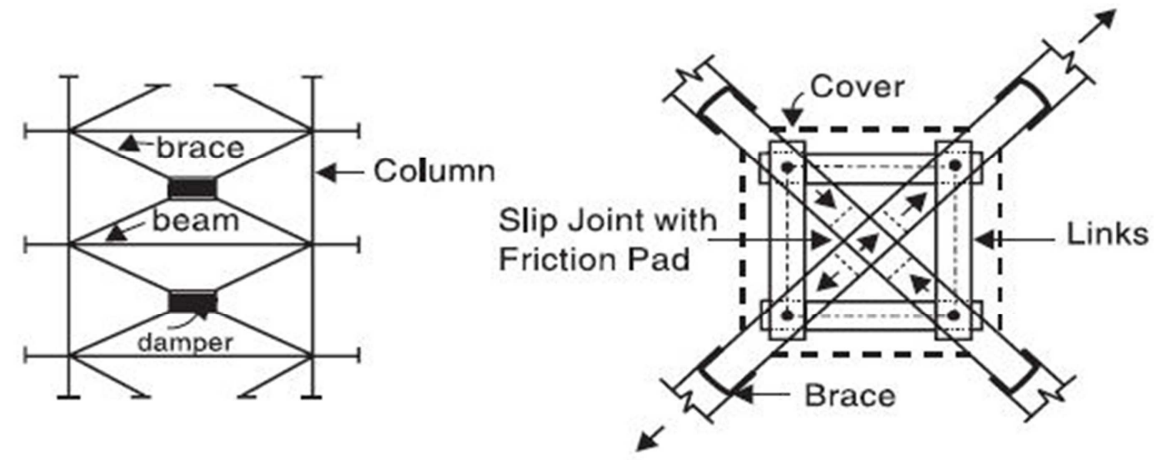

Fig. 4. X-braced friction devices [7]

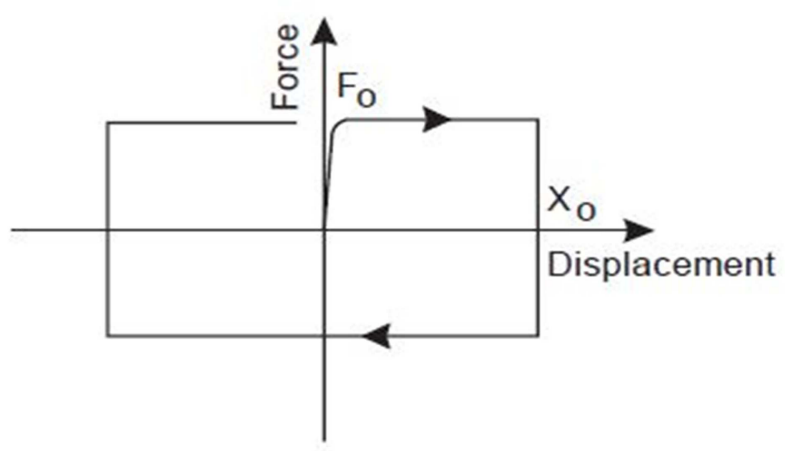

Fig. 5. Idealized force-displacement loop friction device [7] 


\subsection{Viscous fluid devices}

Viscous fluid devices (VFDs) depends on either the fluid shear forces within a device container or on the combination of forced flow through the orifices and the shear resistance of viscous fluid within a container, friction between fluid particles and device components also generate heat and thus dissipate the input energy [11, 48-51]. As the device piston head is stroked, the viscous fluid is forced to flow through the small orifices, resulting in the differential in pressure and high pressure on the one side and low pressure on the other side of the device which can produce substantial forces to resist the relative motion of the VFDs [52].

Several types of viscous materials have been considered to reinforce the stiffness and dynamic characteristics of the primary structure [53-56]. Viscous devices have attained recognition of a significantly efficient approach of earthquake energy dissipation for engineering structures. Application of VFD for buildings and bridges has been significantly increased in the area of viscous devices because of the excellent energy dissipation capacity [57]. The resistance force of a linear type of VFD is described by a dashpot [58], in the case of the linear device the force is the product of velocity across the device and the damping constant. Nevertheless, there are significant advantages of utilizing a non-linear VFD along a resistance force which is proportional to an exponential velocity across the device. That is why the more significant measure of energy can be dissipated at small displacements and low velocity with the non-linear VFDs [59], non-linear VFDs are mostly more appealing and more commonly implemented for vibration control than linear FVDs. In the computional equation of VFDs (2) The resistance force $\mathrm{F}_{\mathrm{R}}$ of VFD equals the product of the velocity $\dot{x}(t)$ of the device and the damping coefficient $\mathrm{C}$ including the velocity exponent $\alpha$ in case of linear device velocity-exponent is $\alpha=1$, and in case of the non-linear VFDs, the velocity exponent ranges from 0.3 to 2.0.

$$
F_{R}(t)=C|\dot{x}(t)|^{\alpha} \operatorname{sgn}(\dot{x}(t))
$$

Several analyses were executed on frames that remain linear throughout the behavior and for which the damper was also linear. Moreover, toggle-braced may be vulnerable to losses in device capability when the VFD is operated at low velocities [60]. Non-linear VFDs are beneficial because they achieve approximately the identical responses reduction in the system reduced damper force, supplemental damping system is more effective in managing the building behavior in term of internal forces [61]. The force-deformation behavior of the VFDs has generally been described by mathematical models consisting of linear springs and dashpots. The VFDs devices behavior is generally dependent on the 
working frequency and can be appropriately represented by the use of a classical Maxwell computational model in which dashpot and spring are in series. VFDs have high energy dissipation capacity, low maintenance cost required, out-ofphase damper forces with the building [62] and quite easy to design linear VFDs. Fig. 6 represents the hysteresis loops at different $\alpha$ values for the fluid viscous device, and typical used fluid viscous device can be seen in Fig. 7.

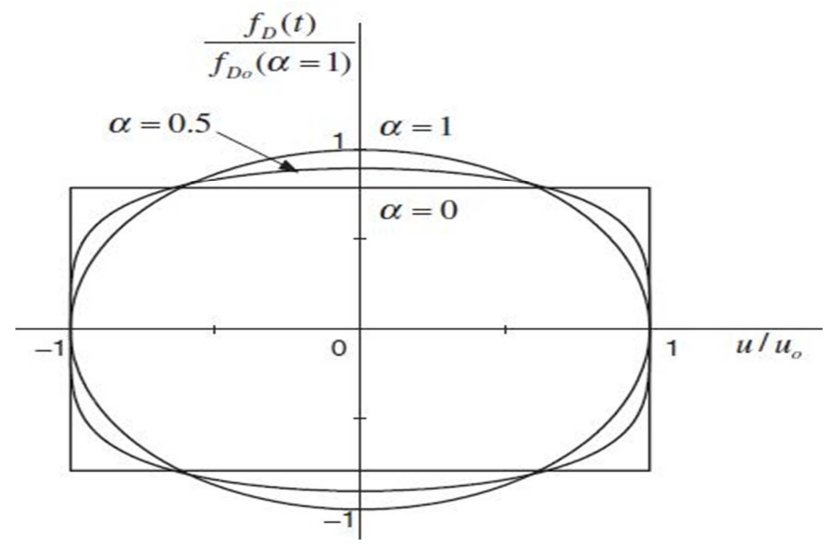

Fig. 6. Hysteresis loops for viscous fluid device [61]

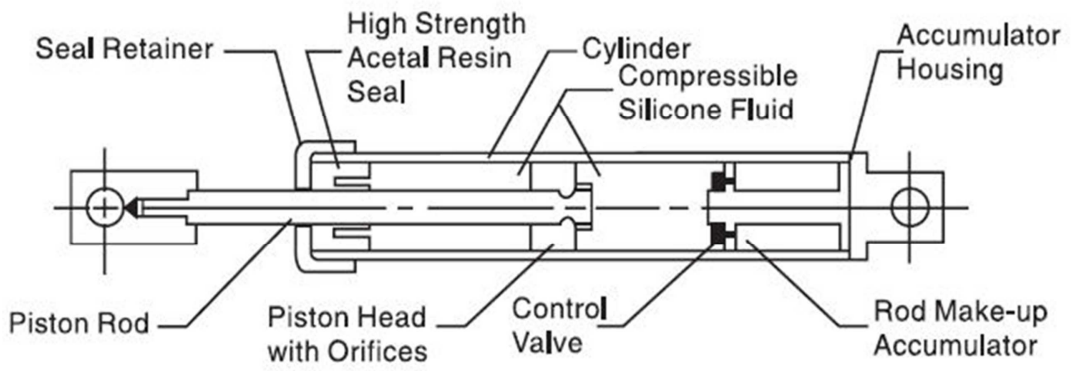

Fig.7. Hysteresis loops for viscous fluid device [61]

\subsection{Viscoelastic devices (VEDs)}

Viscoelastic devices behaviors are dependent on the working frequency, environmental temperature, and the response of these devices may also depend on the displacement. A computational model is being able to identify the behavior of devices under working conditions. VEDs show dynamic properties such as damping and stiffness coefficients, which may be working frequency and temperature dependent. Furthermore, the dynamic force in VEDs is almost proportional to actual velocity. The analytical investigation, advancement of the VEDs and the implementation for earthquake engineering starts in the 1990s. 
The extensive scale tests and the analytical investigation has been proposed and considered for a wide range of building structures over the past few decades. Moreover, the VEDs are most reliable in buildings where the devices undergo shear strain, and force-deformation characteristics depend on working conditions. VEDs are assembled from polymer material layers and supposed to generate the significantly large damping forces through the shear strain in the polymer material. VEDs may be proposed utilizing a Kelvin computational model, where spring part and viscous dashpot are placed parallel [1] and these supplemental devices also contribute to the overall lateral stiffness of frames. When deformation begins, the VE materials exhibit the characteristics of viscous and elastic, after a loading cycle dissipate a limited portion of input energy as heat, and return to their initial stage. Viscoelastic devices response under sinusoidal loading, the stress will be proportional to the strain and the phase angle, and thus the strain has the form and calculated by equation 3 :

$$
\gamma=\gamma_{0} \sin \omega t
$$

Stress can be calculated by equation 4 :

$$
\sigma=\sigma_{0} \sin (\omega t+\delta)
$$

Stress and strain relationship can be expressed by equation 5 and 6 :

$$
\begin{gathered}
\sigma=G^{*} \gamma_{0} \sin (\omega t+\delta) \\
\sigma=\gamma_{0}\left(G_{1} \sin \omega t+G_{2} \cos \omega t\right)
\end{gathered}
$$

Where $G^{*}$ is complex shear modulus $G_{1}$ and $G_{2}$ referred to as the storage and loss modulus respectively. Different vibrant tests of a wide range of several frames with VEDs have been carried out [63-68]. Full-scale viscoelastic coupling damper (VCD) test was performed to control the response for the application of dampers in Toronto and Vancouver, to establish the large displacement demand [69]. A novel VCD device for the building has been developed for accomplishing intensify earthquake and wind dynamic performance of building [70]. VCD connection behavior was linear elastic, and thus the overall VCD behavior was identified by a viscoelastic response [71]. In each of these test studies, VED was found to remarkably enhance the dynamic behavior of the frame and decrease the engineering demand parameters interstory and control the response effectively. These experimental and analytical outcomes utilized to proposed development approach for building added with VEDs. Viscoelastic dampers have been proposed and utilized to retrofit 
buildings frames against severe earthquakes [72-75] and in the construction of new engineering facilities [76].

The effect of the environmental conditions and temperature increase within the viscoelastic material because the cyclic motion has been analyzed and quantified [77-81]. The dependence of the dynamic properties such as stiffness and damping of the viscoelastic devices on the working frequency and shear strain has been considered with different levels of accuracy and working conditions. Researchers have addressed the mathematical modeling issues by considering Maxwell, Kelvin-Voight and hysteretic elements [82-87]. Boltzman superposition principle [88], and fractional derivatives [89-91] have also been proposed to take into the account and predict the dampers behavior considering different parameters. Although these mathematical models can utilize a beneficial purpose in research applications, simplified mathematical models are necessary for design implementations. The commonly used VE device can be seen in Fig 8, the typical force-displacement response of VE devices when subjected to shear deformation can be seen in Fig 9.

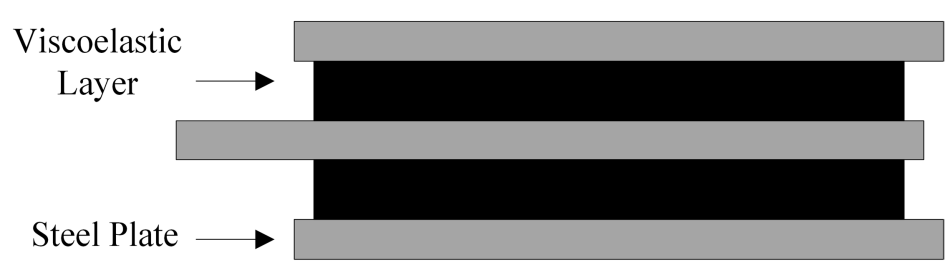

Fig. 8. Typical Viscoelastic device

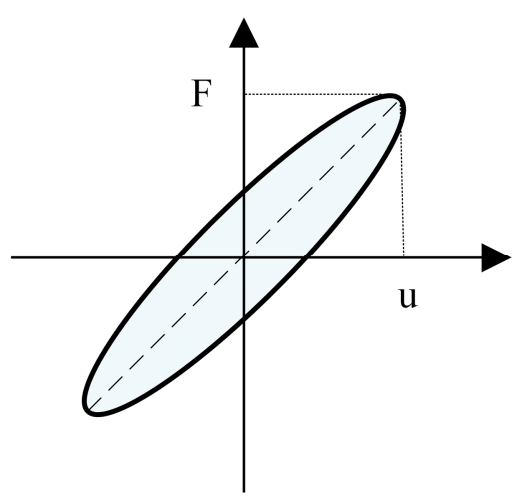

Fig. 9. Force-deformation hysteresis loop of the viscoelastic device 


\section{ENERGY DISSIPATION MECHANISM WITH DEVICES}

Structural damping devices dissipate the particular amount of the vibration energy, results in significantly decreasing vibration energy dissipation demand on primary frame elements and decrease the probable structural damage [7]. Vibration control devices systems based on dynamic energy dissipation mechanism that is maybe because of the lateral movements of the structural systems, nevertheless, reduce the overall dynamic behavior of the structure during seismic events [92]. Damping devices dissipate the significant amount of dissipation, but those devices are not part of the primary structure force resisting and structural stability system; however, they may be replaced after a seismic event.

The energy balance of structure with vibration control devices under earthquake forces found from the integration of the corresponding energy equation concerning the corresponding displacement $\mathrm{x}$. The sum of the kinetic energy of the mass $E_{K}$, viscous damping energy caused by genetic damping and any viscous dampers $E_{D}$, and the strain energy of the structure $E_{A}$ should be equal the corresponding input energy from the earthquake event $\mathrm{E}_{\mathrm{I}}$ [93]. Moreover, $\mathrm{E}_{\mathrm{A}}$ strain energy which is equal to the sum of the $E_{H}$ unrecoverable energy and the strain energy of the actual frame $E_{S}$, where $f_{S}$ is the restoring force and $E_{H}$ depends on the hysteretic characteristics of respective structural elements and any dissipative devices [92]. Some additional parameters are lateral stiffness k, mass $\mathrm{m}$, corresponding velocity $\dot{x}$ and ground acceleration $\ddot{x}_{g}$ :

$$
\begin{gathered}
\int m \ddot{x} d x+\int c \dot{x} d x+\int f_{S} d x=-\int m \ddot{x}_{g} d x \\
E_{K}+E_{D}+E_{A}=E_{I} \\
E_{K}=\int m \ddot{x} d x=\int m \dot{x} d \dot{x}=-\frac{m \dot{x}^{2}}{2} \\
E_{D}=\int c \dot{x} d x=\int c \dot{x}^{2} d t \\
E_{I}=-\int m \ddot{x} g d x \\
E_{A}=E_{S}+E_{H}=\int f_{S} d x \\
E_{S}=\int k x d x=\frac{k x^{2}}{2}
\end{gathered}
$$




\section{INSTALLATION APPROACH}

\subsection{Earlier researches}

Earlier research address the parametric investigation of the shear frame under white noise excitation to optimize the one-story damping coefficient of a multistory [94] and derive the optimum distribution from maximizing the first mode damping ratio for an idealized story frame [63]. Mathematically optimized the placement of a dissipative device in a linear multi-degree of freedom system using an energy criterion [95]. The comprehensive investigation of viscoelastic devices placement concludes that the most exceptional response of a uniform stiffness building was achieved by adding devices on the lower stories [10]. Other researchers studied and validated the SSA approach for viscoelastic devices and to the shear-frame model [96]. Optimization problem and considering torsional effects and locations of devices addressed [97]. High rise buildings are more sensitive to the influence of devices than mid-rise buildings.

\subsection{Analysis and redesign approach (lavan $\mathbf{a} / \mathbf{r}$ approach)}

Analysis and redesign approach is established on a computational method for damper installation, and depends on the foundation of fully-stressed design, and this optimal placement approach utilizes a repetition relation to magnify the vibration control devices consequence on the engineering demand elements such as inter-story drift of the frame and reduce the actual added required damping [98]. Minor modification of the initial analysis and redesign approach utilized to drive the actual damping [99] and showed the Lavan approach to be more effective in terms of story drifts for multiple structures and motions records [14]. The Lavan approach has been validated by gradient-based optimization and has been used for, irregular, industrial and shear frames, and declared this approach attain the optimal design, which may be with a desired homogenous damage distribution, performance-based design aims. The primary motive of the approach is to meet the performance objective considering the actual damping.

\subsection{Standard placement approach}

Stiffness Proportional and uniform damping approach are the basic technique of dividing the actual damping along the height of the building. Homogenous vibration control devices damping may be the useful devices distribution approach in the building, but may or may not be the most efficient and dynamic [100]. Standard placement approach is computionally expressed in equation14 and 15. Uniform damping almost equally distribute the actual damping to each story $\mathrm{C}_{\mathrm{i}}$, such that it is equal to the ratio of total damping $\mathrm{C}_{\mathrm{t}}$ and number of stories $\mathrm{n}$. In the case of relative stiffness approach distribute damping almost 
proportional to the lateral stiffness of each story, And lateral story stiffness may be investigated employing triangular load distribution. The damping to each story is proportional to the ratio of the story Stiffness $\mathrm{K}_{\mathrm{i}}$ and all stories stiffness $\mathrm{K}_{\mathrm{t}}$ :

$$
\begin{gathered}
C_{i}=\frac{C_{t}}{n} \\
C_{i}=C_{t}\left(\frac{K_{i}}{K_{t}}\right)
\end{gathered}
$$

\subsection{Simplified sequential search algorithm (SSSA)}

The simplified sequential search algorithm (SSSA) approach [101] is a heuristic approach for the installation of devices across the structure and develop from the SSA approach [102]. The primary objective of the SSSA approach is to increase the capability of the devices, control the seismic response of the frame. Viscous energy dissipation devices performance is proportional to the device placement at each floor and inter-story velocity. The SSSA optimal location index at floor i described by the inter-story drift, and drift coefficient $\alpha_{1}$ velocity coefficient $\alpha_{2}$ and the inter-story velocity $\dot{\delta}_{i}[101]$ computationally expressed in equation 16 and 17. The viscoelastic device optimal location index depends on the drift and velocity parameters of the index. Nonetheless, the drift coefficient $\alpha_{1}=0$ in the case of the fluid viscous device and the velocity coefficient $\alpha_{2}=1$ and interstory velocity controls the index:

$$
\begin{gathered}
\gamma_{i}=\alpha_{1} \delta_{i}+\alpha_{2} \dot{\delta}_{i} \\
\gamma_{i}=\alpha_{2} \dot{\delta}_{i}+\dot{\delta}_{i}
\end{gathered}
$$

\subsection{Takewaki approach}

The Optimal energy dissipation devices installation for minimum transfer functions [103] approach is a gradient-based research technique for the motive of decreasing the engineering demand parameters such as floor displacement or inter-story drift ratio of the transfer function, classify at the un-damped natural frequency. This technique has been proposed for complicated frames, different building behavior objectives, and other significant important objectives [104]. Generally, energy dissipation devices distribution depends on the lateral response of the building. Takewaki devises distribution approach considers the 
goal of decreasing the engineering demand parameters which is more relevant damage parameters.

\section{ANALYSIS PROCEDURES}

Seismic design codes and guidelines do not address the specific approach for the critical installation of energy dissipation devices according to the structural uncertainties. Structural guidelines, including FEMA 356, FEMA 368, FEMA 450, the International Building Code, BS EN 1998-3 and ASCE/SEI 7-05, address the optimal dampers installation but very limited. Moreover, FEMA 356 and FEMA 368 describe the actual viscous damping supplied by the dampers to meet an effective damping ratio to reduce the vibration.

There are some structural analysis methods available for buildings subjected to earthquake excitation static analysis approach is an immediate approach to find the actual behavior of a building. Primarily, the dynamic analysis approach can be utilized to determine the base shear distribution in a particular axis, along with the building height. In linear static approach, the lateral load is applied to the buildings to find the structural designing forces and displacement. The performance assessment must be investigated utilizing a dynamic approach that mainly accounts for deformations in the structural elements. Generally, the performance indices have a relation among the flexural behavior and strain for static and dynamic loading conditions. Structural linear analysis approach is a quick and easy to estimate the crucial parameters considering engineering demand parameters (FEMA 273/274). Analysis and design of the seismicresistant building are very complicated and complex than the traditional buildings designs because of uncertainties that exist in the computation of estimation of loadings and the engineering demand parameters in the inelastic limit. Building design and analysis codes and guidelines in some cases rely on the comprehensive scientific and approved data collected from over the past few years' analytical research. Calculating dynamic response and the load-bearing capacity of the building is a complex challenge because of the inherent uncertainties of any frame. The flowchart Fig. 10 briefly represents the passive control devices installation approach in building structures.

\section{FUTURE RECOMMENDATIONS}

- Propose the simple enough and accurate approach to analyzing the building with energy dissipation devices which consider all the significant uncertainties, including building material, loading cases, ground motion records, and the dynamic properties of devices. 
- Determine a substantial selection criterion of devices placement approach for post-earthquake structures. Vibration control devices also produce some extra unbalanced axial loads in the columns, which may influence the stability of whole building; however, unbalanced loads must be considered in devices placement approach.

- The credibility of vibration control devices in civil engineering is based on the mechanical performance and cost of devices. However, significant efforts are needed to develop the cost-effective and excellent energy dissipation devices, similarly the verification of their ability to dissipate significant amount of energy during aftershocks exactly after a severe seismic event 


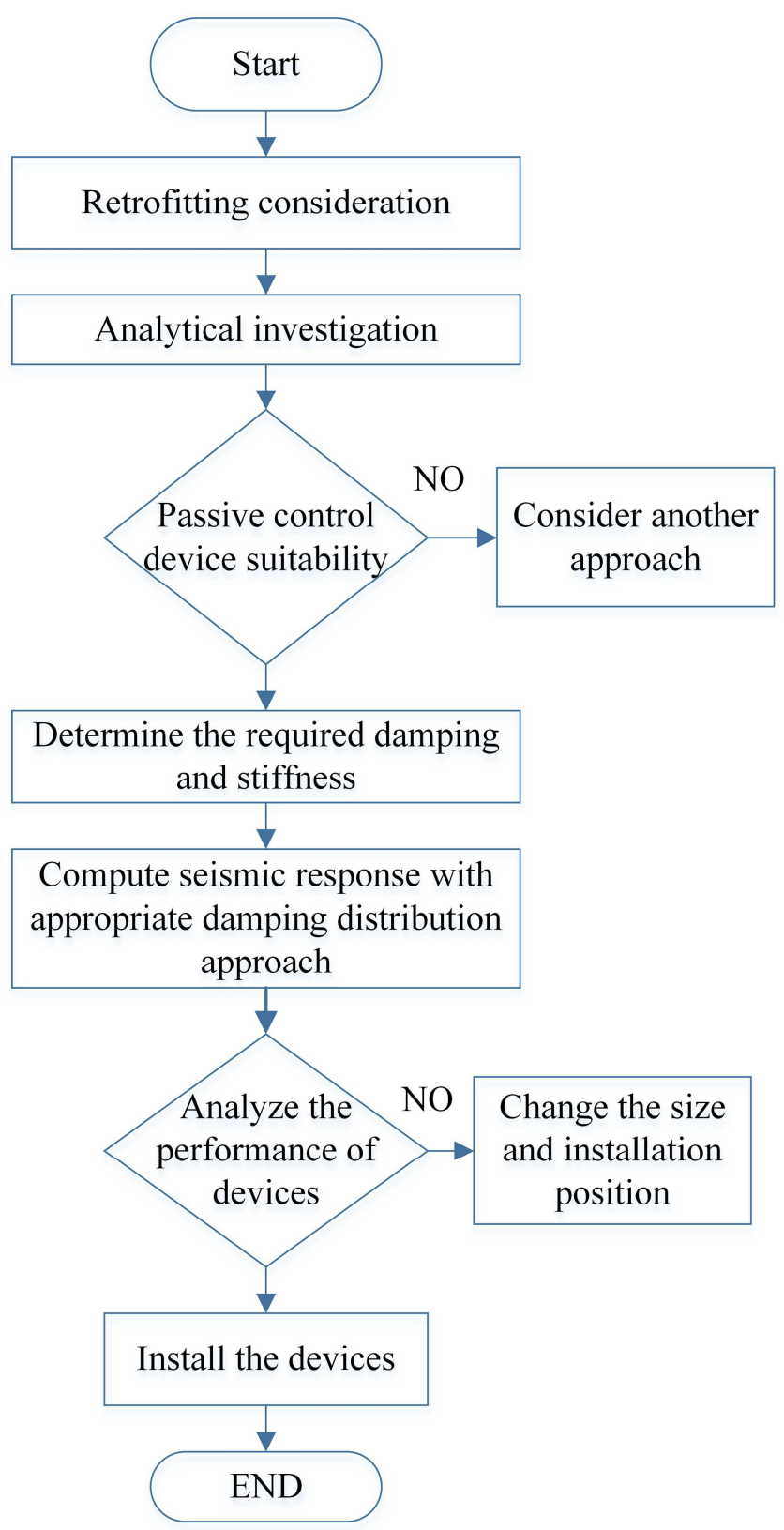

Fig. 10. Passive control system installation approach 


\section{CONCLUDING REMARKS}

This review paper has highlighted comprehensively, the energy dissipation mechanism, effectiveness of vibration control devices, and the importance of installation techniques to control the response of buildings and ensure the performance within economic cost. Vibration control device acts mainly to dissipate input energy, but the primary features of the passive control devices in case of velocity and displacement dependence should be considered in the analysis and real applications. The metallic devices experience uniform flexural deformation across the length of the device, despite the variation in metallic substances. However as the deformation reaches the yielding point, the supplemental stiffness increase the lateral stiffness of buildings and the yielding begin their entire volume. Friction devices differ from the metallic devices principles used to dissipate the input earthquake energy from buildings; the force developed in the friction devices is controlled by the design slip load and strain hardening. The friction devices show significantly stiffening features at their primarily phase and show strengthening afterward, and both are unaffected by working frequency. The hysteretic response of the friction provides the first improvement to the reduction of the dynamic structural response. Scientific analytical models of viscous fluid devices are primarily critical for computational analyses of structures with devices. Since non-linear fluid viscous devices are frequently used in applications due to their significant high energy dissipation capacity. Another preference associated with the fluid devices is that viscous forces are out of phase with supplemental displacement dependent forces, and do not directly adds to the maximum reaction forces developed in the primary building elements.

Viscoelastic devices behavior is linear over a broad range of applied strain; the temperature is constant. At the large deformation, there is an appreciable selfheating because of the significant portion of input energy absorbed, changes the dynamic characteristics of the VE material results in the overall nonlinear response. VE devices add significant damping to buildings for enhanced the dynamic response, hysteretic features of devices. are functions of material type, loading frequency, shear strain level, and working temperature. Vibration control devices placement methods have been reviewed in this paper, but the design codes have approved none of these. After the development of energy dissipation devices, the critical phase of rehabilitation of structure is the damping distributions throughout its floors, the appropriate location of each device directly influence the dynamic response of the building. Seismic resistance design guidelines and building codes do not address the placement methods relative to each vibration control device behavior. 


\section{ADDITIONAL INFORMATION}

This research received no external funding. The authors declare no conflict of interest.

\section{REFERENCES}

1. Federal Emergency Management Agency (FEMA) 1997.NEHRP guidelines for the seismic rehabilitation of buildings. Building Seismic Council, Washington, DC. Reports No. 273 and 274.

2. Kelly, JM, Skinner, RI and Heine, AJ 1972. Mechanism of Energy Absorption in Special Devices for Use in Earthquake Resistant Structures. Bulletin of N.Z.Society for Eartquake Engineering 5(3).

3. Constantinou, MC and Symans, MD 1993. Seismic response of structures with supplemental damping. The Structural Design of Tall Buildings 2, 7792.

4. Hanson, RD 1993. Supplemental Damping for Improved Seismic Performance. Earthquake Spectra 9, 319-334.

5. Hsu, SY and Fafitis, A 1992 Seismic Analysis Design of Frames with Viscoelastic Connections. Journal of Structural Engineering 118, 24592474.

6. Housner, GW, Bergman, LA, Caughey, TK, Chassiakos, AG, Claus, RO, Masri, SF, Skelton, RE, Soong, TT, Spencer, BF, Yao, JTP 1997. Structural Control: Past, Present, and Future. Journal of Engineering Mechanics 123, 897-971.

7. Constantinou, M, Soong, TT and Dargush, GF 1998. Passive Energy Dissipation Systems for Structural Design and Retrofit. MCEER Technical Reports, Monograph No. 1.

8. Soong, TT and Dargush, GF 1997. Passive Energy Dissipation Systems in Structural Engineering. Chichester, England: John Wiley \& Sons Ltd.

9. Liu, W, Tong, M and Lee, GC 2005. Optimization Methodology for Damper Configuration Based on Building Performance Indices. Journal of Structural Engineering 131, 1746-1756.

10. Hahn, GD and Sathiavageeswaran, KR 1992. Effects of added-damper distribution on the seismic response of buildings. Computers \& Structures 43, 941-950.

11. Hanson, RD and Soong, TT 2001. Seismic design with supplemental energy dissipation devices. Second Monograph Series (MNO-8). Earthquake Engineering Research Institute: Oakland, CA. 
12. Xia, C and Hanson, RD 1992. Influence of ADAS Element Parameters on Building Seismic Response. Journal of Structural Engineering 118, 19031918.

13. Martinez-Romero, E 1993. Experiences on the Use of Supplementary Energy Dissipators on Building Structures. Earthquake Spectra 9, 581-625.

14. Gluck, N, Reinhorn, AM, Gluck, J and Levy, R 1996. Design of Supplemental Dampers for Control of Structures. Journal of Structural Engineering, 122, 1394-1399.

15. Kitajima, K, Chikui, H, Ageta, H and Yokouchi, H 2004. Application to response control retrofit method by means of external damping braces using friction dampers. Thirteenth World Conference on Earthquake Engineering. Vancouver, B.C. Canada. Paper No. 2112

16. Bergman, DM and Goel, SC 1987. Evaluation of Cyclic Testing of SteelPlate Devices for Added Damping and Stiffness. University of Michigan, Ann Aarbor, MI.

17. Whittaker, AS, Bertero, VV, Thompson, CL and Alonso, LJ 1991. Seismic Testing of Steel Plate Energy Dissipation Devices. Earthquake Spectra 7, 563-604.

18. Jara, JM, Gomez-Soberon, C, Vargas, E and Gonzalez, R 1993. Seismic Performance of Buildings with Energy Dissipating Systems, in Seminar on Seismic Isolation, Passive Energy Dissipation, and Active Control. San Francisco, CA. p. 663-674.

19. Fierro, EA and Perry, CL 1993. San Francisco Retrofit Design Using Added Damping and Stiffness (ADAS) Elements, in ATC-17-1 Seminar on Seismic Isolation,Passive Energy Dissipation, and Active Control. San Francisco, CA. p. 593-604.

20. Perry, CL, Fierro, EA, Sedarat, Hassan and Scholl, RE 1993. Seismic Upgrade in San Francisco Using Energy Dissipation Devices. Earthquake Spectra 9, 559-579.

21. Youssef, N and Guh, TJ 1993. Seismic Retrofit of Structures with Passive Energy Dissipation Devices, in ATC-17-1 Seminar on Seismic Isolation, Passive Energy Dissipation, and Active Control.: San Francisco, CA. p. 639-650.

22. Nakashima, M, Saburi, K and Tsuji, B 1996. Energy input and dissipation behaviour of structures with hysteretic dampers. Earthquake Engineering \& Structural Dynamics 25, 483-496.

23. Ruiz, SE, Urrego, OE and Silva, FL 1995. Influence of the spatial distribution of energy-dissipating bracing elements on the seismic response of multistorey frames. Earthquake Engineering \& Structural Dynamics 24, 1511-1525. 
24. Tena-Colunga, A 1997. Mathematical modelling of the ADAS energy dissipation device. Engineering Structures 19, 811-821.

25. Tena-Colunga, A and Vergara, A 1997. Comparative study on the seismic retrofit of a mid-rise steel building: steel bracing vs energy dissipation. Earthquake Engineering \& Structural Dynamics 26, 637-655.

26. Ramber, W 1943. Description of Stress-Strain Curves by Three Parameters. National Advisory Committee for Aeronautics; Washington, DC, United States Technical Note 902. https://ntrs.nasa.gov/search.jsp?R=19930081614.

27. Su, Y-F 1990. Seismic Response of Building Structures with Mechanical Damping Devices. $\mathrm{PhD}$ thesis, Department of Civil Engineering, University of Michigan, Ann Arbor, MI. https://deepblue.lib.umich.edu/handle/2027.42/128540.

28. Xia, C 1990. A Study of ADAS Element Parameters and Their Influence on Earthquake Response of Building Structures. PhD thesis, Department of Civil Engineering, University of Michigan, Ann Arbor, MI. https://deepblue.lib.umich.edu/handle/2027.42/128668.

29. Graesser, EJ and Cozzarelli, FA 1991. A Multidimensional Hysteretic Model for Plastically Deforming Metals in Energy Absorbing Devices. National Center for Earthquake Engineering Center, University of New York at Buffalo: Buffalo, NY. Technical Report NCEER-91-0006

30. Dargush, GF and Soong, TT 1995. Behavior of Metallic Plate Dampers in Seismic Passive Energy Dissipation Systems. Earthquake Spectra 11, 545568.

31. Pong, WS,Tsai, CS and Lee, GC 1994. Seismic Study of Building Frames with Added Energy-Absorbing Devices. National Center for Earthquake Engineering Research, University of New York at Buffalo: Buffalo, NY. Technical Report NCEER-94-0016

32. Tsai, CS and Tsai, KC 1995. TPEA Device as Seismic Damper for HighRise Buildings. Journal of Engineering Mechanics 121, 1075-1081.

33. Ciampi, V, De Angelis, M and Paolacci, F 1995. Design of yielding or friction-based dissipative bracings for seismic protection of buildings. Engineering Structures 17, 381-391.

34. Tsai, KC, Chen, HW, Hong, CP and Su, YF 1993. Design of Steel Triangular Plate Energy Absorbers for Seismic-Resistant Construction. Earthquake Spectra 9, 505-528.

35. Pall, AS and Marsh, C 1982. Response of friction damped braced frames. ASCE Journal of the Structural Division 108, 1313-1323.

36. Aiken, ID and Kelly, JM 1990. Earthquake Simulator Testing and Analytical Studies of Two Energy-Absorbing Systems for Multistory 
Structures. Earthquake Engineering Research Center, University of California at Berkeley: Berkeley, CA. Technical Report UCB/EERC 90/03.

37. Cherry, S and Filiatrault, A 1993. Seismic Response Control of Buildings Using Friction Dampers. Earthquake Spectra 9, 447-466.

38. Filiatrault, A and Cherry, S 1987. Performance Evaluation of Friction Damped Braced Steel Frames Under Simulated Earthquake Loads. Earthquake Spectra 3, 57-78.

39. Grigorian, CE, Yang, TS and Popov, EP 1993. Slotted Bolted Connection Energy Dissipators. Earthquake Spectra 9, 491-504.

40. Filiatrault, A and Cherry, S 1988. Comparative performance of friction damped systems and base isolation systems for earthquake retrofit and aseismic design. Earthquake Engineering \& Structural Dynamics 16, 389416.

41. Filiatrault, A and Cherry, S 1989. Efficient numerical modelling for the design of friction damped braced steel plane frames. Canadian Journal of Civil Engineering 16, 211-218.

42. Foti, D, Bozzo, L and López-Almansa, F 1998. Numerical efficiency assessment of energy dissipators for seismic protection of buildings. Earthquake Engineering \& Structural Dynamics 27, 543-556.

43. Pekau, OA and Guimond, R. 1991. Controlling seismic response of eccentric structures by friction dampers. Earthquake Engineering \& Structural Dynamics 20, 505-521.

44. Colajanni, P and Papia, M 1997. Hysteretic Behavior Characterization of Friction-Damped Braced Frames. Journal of Structural Engineering 123, 1020-1028.

45. Roik, K, Dorka, U and Dechent, P 1988. Vibration control of structures under earthquake loading by three-stage friction-grip elements. Earthquake Engineering \& Structural Dynamics 16, 501-521.

46. Nims, DK, Richter, PJ and Bachman, RE 1993. The Use of the Energy Dissipating Restraint for Seismic Hazard Mitigation. Earthquake Spectra 9, 467-489.

47. Filiatrault, A, Tremblay, R and Kar, R 2000. Performance Evaluation of Friction Spring Seismic Damper. Journal of Structural Engineering. 126, 491-499.

48. Makris, N, Roussos, Y, Whittaker, AS and Kelly, JM 1997. Viscous Heating of Fluid Dampers During Seismic and Wind Excitations Analytical Solutions and Design Formulae. Earthquake Engineering Research Center, University of California at Berkeley, Berkeley, CA. Report No. UCB/EERC 97-11. 
49. Makris, N, Roussos, Y, Whittaker, AS and Kelly, JM 1998. Viscous Heating of Fluid Dampers. II: Large-Amplitude Motions. Journal of Engineering Mechanics 124, 1217-1223.

50. Makris, N 1998. Viscous Heating of Fluid Dampers. I: Small-Amplitude Motions. Journal of Engineering Mechanics 124, 1210-1216.

51. Hou, C-Y 2008. Fluid Dynamics and Behavior of Nonlinear Viscous Fluid Dampers. Journal of Structural Engineering 134, 56-63.

52. Lee, D and Taylor, DP 2001. Viscous damper development and future trends. The Structural Design of Tall Buildings 10, 311-320.

53. Constantinou, MC, Symans, M D, Tsopelas, P and Taylor, DP et al 1993. Fluid Viscous Dampers in Applications of Seismic Energy Disipation and Seismic Isolation. Proceedings of ATC-17-1 Seminar on Seismic Isolation, Passive Energy Dissipation, and Active Control, Applied Technology Council, San Francisco California. 2, 581-592.

54. Niwa, N, Kobori, T, Takahashi, M, Hatada, T, Kurino, H and Tagami, J 1995. Passive seismic response controlled high-rise building with high damping device. Earthquake Engineering \& Structural Dynamics 24, 655671.

55. Pekcan, G, Mander, JB and Chen, SS 1995. The Seismic Response of a 1:3 Scale Model R.C. Structure with Elastomeric Spring Dampers. Earthquake Spectra 11, 249-267.

56. Tsopelas, P and M.C. 1994. Constantinou, Experimental and Analytical Study of a System Consisting of Sliding Bearings and Fluid Restoring Force/Damping Devices. NCEER-Taisei Corporation Research Program on Sliding Seismic Isolation System for Bridges: National Center for Earthquake Engineering Research, University of New York at Buffalo: Buffalo, NY.

57. Soneji, BB and Jangid, RS 2007. Passive hybrid systems for earthquake protection of cable-stayed bridge. Engineering Structures 29, 57-70.

58. Taylor, DP 2002. History, design, and applications of fluid dampers in structural engineering. Passive Structural Control Symposium. Tokyo Institute of Technology, Tokyo, Japan.

59. Antonucci, R, Balducci, F, Bartera, F, Castellano, MG, Fuller, K, Giacchetti, R 2004. Shaking table testing of an RC frame with dissipative bracings. Thirteenth World Conference on Earthquake Engineering. Vancouver, BC, Canada. Paper No. 1967.

60. Charney, FA and McNamara, RJ 2008. Comparison of Methods for Computing Equivalent Viscous Damping Ratios of Structures with Added Viscous Damping. Journal of Structural Engineering 134, 32-44. 
61. Lin, W-H and Chopra, AK 2002. Earthquake response of elastic SDF systems with non-linear fluid viscous dampers. Earthquake Engineering \& Structural Dynamics 31, 1623-1642.

62. Paola, MD, Mendola, LL and Navarra, G 2007. Stochastic Seismic Analysis of Structures with Nonlinear Viscous Dampers. Journal of Structural Engineering 133, 1475-1478.

63. Ashour, SA 1987. Elastic Seismic Response of Buildings with Supplemental Damping. PhD thesis, Deptartment of Civil Engineering, University of Michigan: Ann Arbour, Michigan. https://www.osti.gov/biblio/5340235-elastic-seismic-response-buildingsupplemental-damping.

64. Chang, KC, Soong, TT, Oh, S-T and Lai, ML 1995. Seismic Behavior of Steel Frame with Added Viscoelastic Dampers. Journal of Structural Engineering 121, 1418-1426.

65. Foutch, DA, Wood, SL and Brady, PA 1993. Seismic Retrofit of Nonductile Reinforced Concrete Using Viscoelastic Dampers. Proceedings of ATC-17-1 Seminar on Seismic Isolation, Passive Energy Dissipation, and Active Control, Applied Technology Council, San Francisco California 2, 605-616.

66. Min, K-W, Kim, J and Lee, S-H 2004. Vibration tests of 5-storey steel frame with viscoelastic dampers. Engineering Structures 26, 831-839.

67. Bergman, DM and Hanson, RD 1993. Viscoelastic Mechanical Damping Devices Tested at Real Earthquake Displacements. Earthquake Spectra 9, 389-417.

68. Lobo, RF, Bracci, JM, Shen, KL, Reinhorn, AM and Soong, TT 1993. Inelastic Response of R/C Structures with Viscoelastic Braces. Earthquake Spectra 9, 419-446.

69. Montgomery, M and Christopoulos, C 2015. Experimental Validation of Viscoelastic Coupling Dampers for Enhanced Dynamic Performance of High-Rise Buildings. Journal of Structural Engineering 141, 04014145.

70. Christopoulos, C and Montgomery, M 2013. Viscoelastic coupling dampers (VCDs) for enhanced wind and seismic performance of high-rise buildings. Earthquake Engineering \& Structural Dynamics 42, 2217-2233.

71. Montgomery, MS 2011. Fork configuration dampers (FCDs) for enhanced dynamic performance of high-rise buildings. $\mathrm{PhD}$ thesis, Deptartment of Civil Engineering, University of Toronto: Toronto, Canada.

72. Crosby, P, Kelly, JM and Singh, Y 1994. Utilizing Viscoelastic Dampers in the Seismic Retrofit of a Thirteen Story Steel Frame Building. In 12th Structures Congress. Atlanta, GA. 1286-1291. 
73. Hendsbee, D 1993. Retrofit of a Concrete Frame Building Using Added Damping. Proceedings of ATC-17-1 Seminar on Seismic Isolation, Passive Energy Dissipation, and Active Control, Applied Technology Council, San Francisco California 2, 617-626.

74. Kanitkar, R, Harms, M, Lai, ML and Crosby, P 1998. Linear and NonLinear Analysis of a Four Story Structure Using Viscoelastic Dampers, In sixth U.S. National Conference on Earthquake Engineering. Seattle, WA.

75. Rai, DC 1999. Supplemental damping for seismic strengthening: a case study. Engineering Structures 21, 603-614.

76. Miranda, E, Alonso, J and Lai, ML 1998. Performance-Based Design of a Building in Mexico City Using Viscoelastic Devices. In sixth US National Conference on Earthquake Engineering. Seattle, WA.

77. Aprile, A, Inaudi, JA and Kelly, JM 1997. Evolutionary Model of Viscoelastic Dampers for Structural Applications. Journal of Engineering Mechanics 123, 551-560.

78. Chang, KC, Soong, TT, Oh, S-T and Lai, ML 1992. Effect of Ambient Temperature on Viscoelastically damped structure. Journal of Structural Engineering 118, 1955-1973.

79. Tsai, CS 1994. Temperature Effect of Viscoelastic Dampers during Earthquakes. Journal of Structural Engineering 120, 394-409.

80. Chang, K-C and Lin, Y-Y 2004. Seismic Response of Full-Scale Structure with Added Viscoelastic Dampers. Journal of Structural Engineering 130, 600-608.

81. Fan, CP 1998. Seismic analysis, behavior, and retrofit of non-ductile reinforced concrete frame buildings with viscoelastic dampers. Department of Civil and Environmental Engineering. Lehigh University, Bethlehem, PA.

82. Inaudi, JA 1997. Analysis of Hysteretic Damping Using Analytic Signals. Journal of Engineering Mechanics 123, 743-745.

83. Inaudi, JA and Kelly, JM 1995. Linear hysteretic damping and the hilbert transform. Journal of Engineering Mechanics 121, 626-632.

84. Inaudi, JA and Kelly, JM 1995. Modal equations of linear structures with viscoelastic dampers. Earthquake Engineering \& Structural Dynamics 24, 145-151.

85. Inaudi, JA and Makris, N 1996. Time-domain analysis of linear hysteretic damping. Earthquake Engineering \& Structural Dynamics 25, 529-545.

86. Makris, N 1997. Causal Hysteretic Element. Journal of Engineering Mechanics 123, 1209-1214.

87. Makris, N, Inaudi, JA and Kelly, JM 1996. Macroscopic models with complex coefficients and causality. Journal of Engineering Mechanics 122, 566-573. 
88. Shen, KL and Soong, TT 1995. Modeling of Viscoelastic Dampers for Structural Applications. Journal of Engineering Mechanics 121, 694-701.

89. Bagley, RL and Torvik, J 1983. Fractional calculus - A different approach to the analysis of viscoelastically damped structures. AIAA Journal 21, 741748.

90. Tsai, CS and Lee, HH 1993. Applications of Viscoelastic Dampers to HighRise Buildings. Journal of Structural Engineering 119, 1222-1233.

91. Kasai K, Munshi, JA, Lai, ML and Maison BF 1993. Viscoelastic Damper Hysteretic Model: Theory, Experiment, and Application. Proceedings of ATC-17-1 Seminar on Seismic Isolation, Passive Energy Dissipation, and Active Control, Applied Technology Council, San Francisco California. 2, 521-532.

92. Christopoulos, C and Filiatrault, A 2006. Principles of Passive Supplemental Damping and Seismic Isolation. Pavia, Italy: IUSS Press.

93. Uang, C-M and Bertero, VV 1990. Evaluation of seismic energy in structures. Earthquake Engineering \& Structural Dynamics 19, 77-90.

94. Constantinou, MC and Tadjbakhsh, IG 1983. Optimum design of a first story damping system. Computers \& Structures 17, 305-310.

95. Gürgöze, M and Müller, PC 1992. Optimal positioning of dampers in multi-body systems. Journal of Sound and Vibration 158, 517-530.

96. Shukla, AK and Datta, TK 1999. Optimal Use of Viscoelastic Dampers in Building Frames for Seismic Force. Journal of Structural Engineering 125, 401-409.

97. $\mathrm{Wu}, \mathrm{B}, \mathrm{Ou}, \mathrm{J}-\mathrm{P}$ and Soong, TT 1997. Optimal placement of energy dissipation devices for three-dimensional structures. Engineering Structures 19, 113-125.

98. Levy, R and Lavan, O 2006. Fully stressed design of passive controllers in framed structures for seismic loadings. Structural and Multidisciplinary Optimization 32, 485-498.

99. Levy, R and Lavan, O 2009. Quantitative Comparison of Optimization Approaches for the Design of Supplemental Damping in Earthquake Engineering Practice. Journal of Structural Engineering 135, 321-325.

100. Singh, MP and Moreschi, LM 2002. Optimal placement of dampers for passive response control. Earthquake Engineering \& Structural Dynamics 31, 955-976.

101. Garci'a, D.L.p 2001. A Simple Method for the Design of Optimal Damper Configurations in MDOF Structures. Earthquake Spectra 17, 387-398.

102. Zhang, RH and Soong, TT 1992. Seismic Design of Viscoelastic Dampers for Structural Applications. Journal of Structural Engineering 118, 13751392. 
103. Takewaki, I 1997. Optimal damper placement for minimum transfer functions. Earthquake Engineering \& Structural Dynamics 26, 1113-1124.

104. Takewaki, I 2009. Building Control with Passive Dampers: Optimal Performance-based Design for Earthquakes. John Wiley \& Sons. London, U.K.

Editor received the manuscript: 02.04.2019 